\title{
BIODIVERSITY AND ECOSYSTEM FUNCTIONAL ENHANCEMENT BY FOREST RESTORATION: A META-ANALYSIS IN CHINA
}

\author{
Yanjiao Ren ${ }^{1,2}$ (D), Yihe Lü ${ }^{1,2,3 *}$, Bojie Fu ${ }^{1,2,3}$, Kun Zhang ${ }^{1,2}$ \\ ${ }^{1}$ State Key Laboratory of Urban and Regional Ecology, Research Center for Eco-environmental Sciences, Chinese Academy of Sciences, PO Box 2871 , Beijing \\ 100085, PR China \\ ${ }^{2}$ University of Chinese Academy of Sciences, Beijing 100049, PR China \\ ${ }^{3}$ Joint Center for Global Change Studies, Beijing 100875, PR China
}

Received 4 January 2017; Revised 21 February 2017; Accepted 21 February 2017

\begin{abstract}
Large-scale forest loss and degradation have dire consequences for biodiversity maintenance and provision of vital ecosystem services. Despite recent increasing efforts for forest restoration and sustainable management, there have been no comparative studies of biological taxonomy and multiple ecosystem functions to assess the effectiveness of forest restoration programmes, and how they vary through space and time. Here, we provided a quantitative assessment of the recovery of biodiversity and ecosystem functions by forest restoration in China using a meta-analysis of 172 studies. We found that biodiversity and ecosystem functions were substantially increased in restored forests comparing with the degraded states. However, these restoration effects varied considerably by degradation origin, restoration approach, restoration age, ecological domains, taxonomic group and ecosystem function that is measured. Results also revealed that forest restoration from degraded states could not lead to full recovery of biodiversity and ecosystem functions, highlighting the irreplaceability of primary forests. We advocate allowing for natural or passive recovery, especially where biophysical conditions are favourable for spontaneous succession, or too harsh for human-aided restoration, and choosing a combination of passive and active restoration measures based on adaptive management strategies. Our meta-analysis provided fundamental insights into bridging the gap between small-scale experiments and broad-scale management needs towards highly effective and sustainable forest ecosystem restoration. Copyright @ 2017 John Wiley \& Sons, Ltd.
\end{abstract}

KEY WORDS: biodiversity conservation; ecosystem functions; forest restoration; meta-analysis; spatiotemporal variability

\section{INTRODUCTION}

The world's forests cover nearly one-third of the land area and play a vital role in maintaining biodiversity and ecosystem functions, as well as providing ecosystem services on local, regional and global scales (Aerts \& Honnay, 2011). Despite these benefits, an estimated two billion hectares of forests is degraded worldwide (Stanturf et al., 2014), largely because of agricultural expansion and land uses related to urban population growth (Ahrends et al., 2010; DeFries et al., 2010; Liu et al., 2014). To combat these ongoing losses, many ecological restoration projects and policy initiatives have been implemented in different countries over the past two decades. Among these, the most notable are the 2020 targets from the Convention on Biological Diversity to restore at least $15 \%$ of degraded ecosystems (CBD, 2010) and the Bonn Challenge to restore 150 million hectares of the world's degraded and deforested lands by 2020 and 350 million hectares by 2030 (Jacobs et al., 2015).

Forest restoration is playing an increasingly central role in global and Chinese environmental policies for

\footnotetext{
*Correspondence to: Y. Lü, Research Center for Eco-Environmental Sciences, Chinese Academy of Sciences, \#18 Shuangqing Road, Haidian District, Beijing 100085, PR China.

E-mail: 1yh@rcees.ac.cn
}

enhancing biodiversity and ecological security, as well as improving human livelihoods. The area of forest land has increased from 195 to 208 million hectares during 20092013 in China (SFA, 2014). Despite this increment, China's forest coverage remains under the world average of $31 \%$. Furthermore, there are several problems with these forests, including highly uneven distribution, low ecosystem heterogeneity, poor structure, low soil fertility and overuse of ornamental species coupled with insufficient concerns for their ecological functions (Ren et al., 2011). To improve the conditions of forests in China, several forest-restoration-related programmes have been formally implemented, such as the key State Forestry development programmes including the natural forest protection programme, key forest shelterbelt construction programme, Grain-for-Green programme and wildlife conservation and nature reserve development programme (Li, 2004).

Biodiversity and ecosystem functions are key components of forests, as well as major objectives for forest restoration practices. Many restoration programmes have been focused on historical forest composition and structure in small areas, such as forest stands (Lamb et al., 2012). Stanturf et al. (2014) summarized the major contemporary restoration objectives of forests as follows: repair of hydrologic functions, coastal protection, geologic protection, carbon sequestration, enhancement of species or landscape diversity 
and enhancement of livelihoods (wood productions, nontimber forest products and wildlife habitat). The setting of restoration objectives is conditioned by the scale, social context and expected degrees of recovery. Given the large areas in need of ecological restoration, a functional perspective on the objective of restoration becomes more urgent and effective than traditional approaches (Oliver, 2014). Ecological restoration has recently started to adopt insights from the biodiversity-ecosystem functioning perspective, which offers a comprehensive framework for effective restoration (Aerts \& Honnay, 2011). Efforts to synthetically evaluate the effectiveness of ecological restoration have been made in specific ecosystem types such as agroecosystems (Barral et al., 2015), wetlands (Moreno-Mateos et al., 2012; Meli et al., 2014; Moreno-Mateos et al., 2015) and forests (Marín-Spiotta et al., 2013; Crouzeilles et al., 2016; Crouzeilles \& Curran, 2016) on regional or global scale. To our knowledge, however, there are few systematically quantitative studies on biodiversity and multiple ecosystem functions in a forest context in China, regardless of implementing numerous forest restoration programmes with various objectives. Most studies provided limited insights into the varied responses of biodiversity and ecosystem functions to forest restoration because they are understandably restricted to particular taxa and geographic regions (Ren et al., 2007; Ding et al., 2012; Tang et al., 2013; Liang et al., 2015). Therefore, their often-contrasting conclusions might have clouded ongoing debates over the effectiveness of forest restoration programmes.

The vast amount of degraded forests implies that the practice of restoration must be performed efficiently at all decision phases and levels, from interior stands to landscapes. Recent scientific literature synthesizing the results of former restoration projects indicated that past experiences in ecological restoration must be capitalized upon to accomplish growing restoration needs for the future (Rey Benayas et al., 2009; Liao et al., 2012; Spake et al., 2015), which is also helpful for determining whether current restoration is working and then learning from past actions using an adaptive approach (Jacobs et al., 2015). A comprehensive meta-analysis synthesizing former forest restoration practices across biological taxa and geographic regions is therefore sorely a research priority.

Here, we analysed the potential influence factors of forest restoration and quantified the recovery levels of biodiversity (driven mostly by biotic assemblages) and multiple ecosystem functions (driven primarily by the storage of carbon, nitrogen, phosphorus, biomass and organic matter) in China's forests. In our study, we addressed two fundamental questions: (1) how do biodiversity and ecosystem functions respond to forest restoration and (2) what factors (i.e. degradation origin, restoration approach, restoration age and ecological domains) affect recovery effectiveness? Our study provided a stepping stone and preliminary framework for quantitative synthesis of biodiversity and ecosystem functions in a forest restoration context.

\section{MATERIAL AND METHODS}

\section{Literature Search}

We conducted a systematic reference search in the scientific database ISI Web of Science (http://www. isiwebofknowledge.com) and the China National Knowledge Infrastructure (http://www.cnki.net/) with no restriction on publication year. We used the following combination of terms: '(forest*) AND (restor* or recreat* or rehabilitat* or enhance* or reforest* or afforest* or recover*) AND (biodiversity or ecosystem function*) AND (China)'. The deadline for the search was 30 June 2016. We focused on screening the title, keywords and abstract of the references to identify those likely to report information related to our study, which resulted in a list of 1,164 references. We then scanned these references to assess the potential for satisfying the selection criteria, yielding 195 references. We also screened the cited references of the potential study candidates. And we read over the references and included those that (i) were conducted in forest ecosystems in China; (ii) included measures of biodiversity, ecosystem functions or both at multiple sampling locations (replicates for restored and degraded and/or reference forests); (iii) reported specific mean value, sample size and standard deviation or error of each variable for biodiversity and ecosystem functions; and (iv) included known restoration age. We defined reference forests as natural old-growth or lessdisturbed forests based on the definition presented in former studies (Rey Benayas et al., 2009; Curran et al., 2014). After this exhaustive literature search, we obtained a list of 172 articles that were included in our meta-analysis (Appendix S1).

\section{Data Extraction and Database Building}

We recorded for each study the following data: (i) basic information of study sites (province, latitude and longitude, altitude and climate type), (ii) initial state (farmland/ degraded woodland), (iii) degradation origin (agriculture/ logging/mining/natural disaster), (iv) restoration age, (v) restoration approach (active/passive), (vi) geographic region, (vii) measured variables of biodiversity and ecosystem functions and units, and (viii) the mean values, standard deviation and sample size of the measured variables for restored and degraded (or reference) forest. The geographic region was represented by four ecological domains: northern arid and semi-arid, north-eastern humid and semi-humid, Tibet Plateau and southern humid, which is proposed by Xie et al. (2012) based on climate, topography and ecosystem characteristics (Figure 1). We also selected four representative ecoregions, a lower geographic region division than the ecological domain, for further analysis of the geographical variation of biodiversity and ecosystem function recovery, as follows: Loess Plateau ecoregion, Sichuan-Chongqing ecoregion, Yunnan-Guizhou Plateau ecoregion and South China ecoregion. We broadly differentiated biodiversity into three taxonomic groups (vegetation, invertebrate and soil microorganism) and ecosystem functions into six groups (carbon storage and cycling, nitrogen storage and cycling, phosphorus storage, other element 


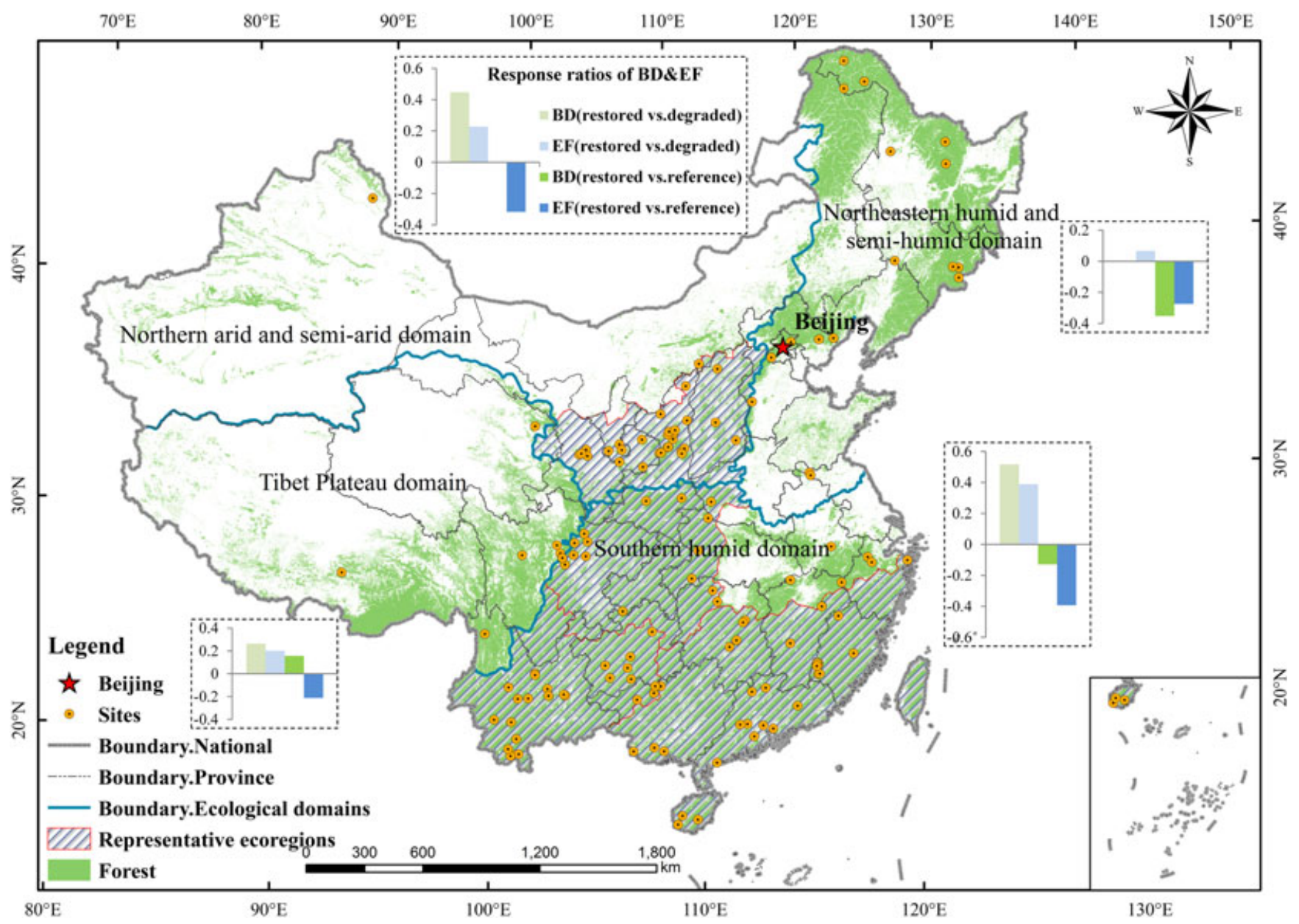

Figure 1. Distribution of the 172 studies and their reported degrees of biodiversity and ecosystem function recovery across ecological domains. Only statistically significant results (i.e. the bias-corrected $95 \%$ confidence intervals did not overlap zero) were shown in the bar charts. $\mathrm{BD}=$ biodiversity; $\mathrm{EF}=$ ecosystem functions. [Colour figure can be viewed at wileyonlinelibrary.com]

storage, biomass and production, and organic matter accumulation). Variables used to measure biodiversity and ecosystem functions were included in Tables I, S2 and S3. Data of the measured variables were extracted from tables, figures and main text of the selected articles. For data expressed in figures, the Engauge Digitizer 4.1 was used to obtain the exact values.
We built two separate databases for restored versus degraded and restored versus reference ecosystems (Tables S4 and S5). The former was used to evaluate the actual degree of biodiversity and ecosystem function recovery, and the latter was to assess the gap and difference between present forests and the less-disturbed forests (benchmark).

Table I. Variables measured simultaneously in restored and degraded (or reference) ecosystems to estimate forest restoration effectiveness

\begin{tabular}{|c|c|c|}
\hline Forest biodiversity/ecosystem functions & $N$ & Measured variables \\
\hline \multicolumn{3}{|l|}{ Biodiversity } \\
\hline Vegetation & 1,089 & Diversity, abundance, density, richness, coverage \\
\hline Invertebrate & 238 & Diversity, richness, density \\
\hline Soil microorganism & 904 & Diversity, richness, number, biomass \\
\hline \multicolumn{3}{|l|}{ Ecosystem functions } \\
\hline Carbon storage and cycling & 1,107 & Soil organic carbon and microbial biomass carbon, mineralizable $\mathrm{C}$ \\
\hline Nitrogen storage and cycling & 1,211 & Soil total and available nitrogen, microbial biomass nitrogen \\
\hline Phosphorus storage & 770 & Soil total and available phosphorus, microbial biomass phosphorus \\
\hline Other elements storage & 768 & Soil K, Ca, Mg, Na, Fe, Mn, Zn \\
\hline Biomass and production & 201 & Biomass of herb/shrub/arbour/community, community net productivity \\
\hline Organic matter accumulation & 2,292 & Soil organic matter, moisture, bulk density, texture, soil enzyme \\
\hline
\end{tabular}

Only the most frequently measured variables were included (see Tables S2 and S3 for a full description of the variables for biodiversity and ecosystem functions). $N=$ sample size of the measured variables. 


\section{Response Ratio Calculation and Meta-analysis}

To standardize and compare data, we used the weighted response ratios (effect size), $\ln \left(X_{\mathrm{e}} / X_{\mathrm{c}}\right)$, where $X_{\mathrm{e}}$ represents the mean values for experimental groups and $X_{\mathrm{c}}$ is for that of control groups. In our study, the experimental group was the restored forest, and there were two control groups, the degraded and the reference forest. Therefore, in our meta-analysis, response ratios were calculated as $\ln \left(X_{\text {rest }}\right)$ $\left.X_{\text {deg }}\right)$ or $\ln \left(X_{\text {rest }} / X_{\text {ref }}\right)$, where $X_{\text {rest }}, X_{\text {deg }}$ and $X_{\text {ref }}$ are the mean values of the same variables in restored, degraded and reference forests, respectively. Following other similar meta-analyses, we converted the sign of data that higher values are associated with lower levels of biodiversity and ecosystem function recovery, such as soil bulk density and content of heavy metal contamination (Rey Benayas et al., 2009; Crouzeilles et al., 2016). Response ratios cannot be calculated for a quantified variable with a zero value. Thus, we excluded comparisons that had zero values for restored, degraded or reference forests.

We compared datasets of restored versus degraded and restored versus reference forest for each taxonomic group and measurements of ecosystem functions. We used a random-effect model, and the bias-corrected 95\% confidence interval (CI) was generated by a bootstrapping procedure based on 999 iterations (Rosenberg et al., 2000). When the effects of restoration age are analysed, mean effect sizes and CIs (95\%) were calculated at successive age clusters of ten consecutive years for all the selected data points. Mean effect sizes were significantly different from one another if their $95 \%$ CIs did not overlap and significantly different from zero if the $95 \%$ CIs did not overlap zero (Gurevitch \& Hedges, 2001).

We used Rosenthal's fail-safe number and funnel plots to check for publication bias, and both indicated that there was no publication bias in our study (Appendix S2) (Rosenthal, 1979; Rosenberg, 2005). Therefore, we believe that the results of our meta-analysis are reliable. All the analyses were performed using METAWIN 2.1.

\section{Potential Influence Factors of Forest Restoration}

We used the linear mixed-effects models to identify which factors from our databases had significant effects on forest restoration and selected them to study the effectiveness of biodiversity and ecosystem function recovery. We evaluated a total of five potential influence factors of the effectiveness of forest restoration as follows: initial state, degradation origin, restoration approach, restoration age and ecological domains. Similar to previous studies (Cole et al., 2014; Spake et al., 2015; Zhang et al., 2016), we compared multiple candidate models that may predict effective restoration including different combinations of potential explanatory variables. The models included a set of five potential explanatory variables and all possible subsets of them. Initial state, degradation origin, restoration approach and ecological domains were categorical predictors, and restoration age was a numeric factor. The five potential explanatory variables were set as fixed-effect terms, and study sites were set as random-effect terms to obviate potential bias resulting from pseudo-replication (Cole et al., 2014). Given the difficulty occasionally found in interpreting results derived from heterogeneous meta-analytical databases and the complexity of potential explanatory variables, we only included main effects in our models and ignored interactions (MorenoMateos et al., 2015).

We calculated for each model the Akaike information criterion corrected for small samples $\left(\mathrm{AIC}_{\mathrm{c}}\right)$. The model with lowest $\mathrm{AIC}_{\mathrm{c}}$ was the most plausible to explain a substantial proportion of variance in the data and was the best-fit model (Burnham, 2002). All the preceding analyses were conducted using the Mixed Procedure in SAS 9.3 (Appendix S3).

We identified the main influence factors when comparing restored and degraded forest for biodiversity and ecosystem functions (Table II). Among the five potential explanatory variables, initial state was not included in both the

Table II. Results of linear mixed-effects models for biodiversity and ecosystem functions in comparisons of restored versus degraded forests

\begin{tabular}{|c|c|c|c|c|}
\hline \multirow[t]{2}{*}{ Model } & \multicolumn{2}{|c|}{ Coefficients } & \multirow[t]{2}{*}{$\mathrm{AIC}_{\mathrm{c}}$} & \multirow[t]{2}{*}{$n$} \\
\hline & Estimate & $\begin{array}{l}\text { Standard } \\
\text { error }\end{array}$ & & \\
\hline Biodiversity & & & $2,156 \cdot 0$ & 943 \\
\hline \multicolumn{5}{|l|}{ Degradation origin } \\
\hline Agriculture & -0.4638 & $0 \cdot 3792$ & & \\
\hline Logging & $-0 \cdot 38$ & $0 \cdot 3549$ & & \\
\hline Mining & $0 \cdot 224$ & $0 \cdot 3966$ & & \\
\hline \multicolumn{5}{|l|}{ Restoration approach } \\
\hline Active & $-0 \cdot 2886$ & $0 \cdot 1368$ & & \\
\hline Restoration age & $0 \cdot 004329$ & $0 \cdot 00114$ & & \\
\hline \multicolumn{5}{|l|}{ Ecological domains } \\
\hline North-eastern & $-0 \cdot 7055$ & $0 \cdot 6044$ & & \\
\hline $\begin{array}{l}\text { humid and semi- } \\
\text { humid domain }\end{array}$ & & & & \\
\hline Northern arid & 0.04819 & 0.4399 & & \\
\hline $\begin{array}{l}\text { and semi-arid } \\
\text { domain }\end{array}$ & & & & \\
\hline $\begin{array}{l}\text { Southern humid } \\
\text { domain }\end{array}$ & $0 \cdot 06308$ & $0 \cdot 3808$ & & \\
\hline Ecosystem functions & & & $6,849 \cdot 4$ & 3,735 \\
\hline \multicolumn{5}{|l|}{ Restoration approach } \\
\hline Active & $-0 \cdot 1206$ & $0 \cdot 03973$ & & \\
\hline Restoration age & $0 \cdot 003152$ & $0 \cdot 00048$ & & \\
\hline \multicolumn{5}{|l|}{ Ecological domains } \\
\hline $\begin{array}{l}\text { North-eastern } \\
\text { humid and semi- } \\
\text { humid domain }\end{array}$ & $-0 \cdot 3687$ & $0 \cdot 3707$ & & \\
\hline $\begin{array}{l}\text { Northern arid } \\
\text { and semi-arid } \\
\text { domain }\end{array}$ & $-0 \cdot 2398$ & $0 \cdot 3611$ & & \\
\hline $\begin{array}{l}\text { Southern humid } \\
\text { domain }\end{array}$ & $-0 \cdot 04308$ & $0 \cdot 3466$ & & \\
\hline
\end{tabular}

Only the best-fit model, with the lowest $\mathrm{AIC}_{c}$, is shown (see Table $\mathrm{S} 7$ for the complete results of model comparison). $n=$ sample size; $\mathrm{AIC}_{\mathrm{c}}=$ Akaike information criterion corrected for small samples. In the analysis of biodiversity, degradation origin (natural disaster), restoration approach (passive) and ecological domains (Tibet Plateau domain) were set as the reference groups for the initial model output. As for ecosystem function analysis, restoration approach (passive) and ecological domains (Tibet Plateau domain) were set as the reference groups. 
biodiversity model and the ecosystem function model. Restoration approach, restoration age and ecological domains were included in the best-fit models for both biodiversity and ecosystem functions, and degradation origin was only included in the biodiversity model.

\section{RESULTS}

\section{Forest Restoration Enhances Biodiversity and Ecosystem Functions}

Values for measures of biodiversity and ecosystem functions were significantly higher in the restored than degraded forest but significantly lower in the restored than reference forest (Figure 2). Differences between restored and degraded forests were higher for biodiversity $(>0 \cdot 2)$ than for ecosystem functions $(>0 \cdot 1)$ and varied among taxonomic groups and measurements of ecosystem functions. Differences between restored and reference forests, however, were lower for biodiversity (greater than -0.17) than for ecosystem functions (greater than -1.04). Measurements of biodiversity and ecosystem functions were $22-196 \%$ and 11$319 \%$, respectively, higher in the restored forest than in the degraded forest, and 10-15\% and 19-65\% lower in the restored forest than in the reference forest, respectively (Table S6).

\section{Biodiversity Recovery from Different Degradation Origins}

Across different degradation origins, biodiversity recovery varied greatly (Figure 3). Values for measures of biodiversity were significantly higher in restored forests than in degraded systems, with mean response ratios ranging from $0 \cdot 21$ to $1 \cdot 22$. The increment of biodiversity was significantly lower in areas influenced by logging than that of the other three degradation origins of agriculture, mining and natural disasters. In comparisons of restored and reference forests, no significant differences were observed in the measurements of biodiversity at areas degraded by agricultural activities and natural disasters. However, in the areas subject to logging and mining, the measurements of biodiversity were significantly lower in restored states than in reference

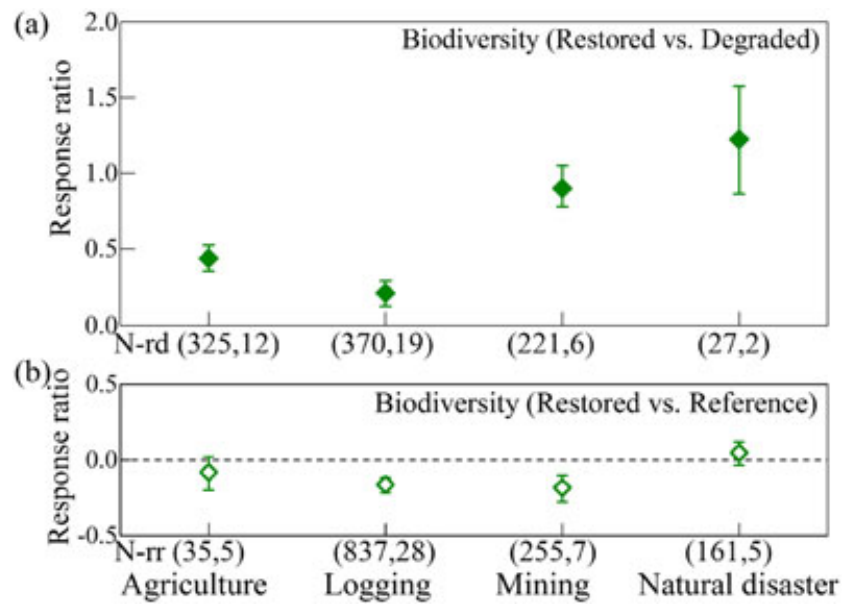

Figure 3. Mean response ratios of biodiversity following different degradation origins. Comparisons between (a) restored and degraded forests and (b) restored versus reference forest. The dashed line at zero represents that measurements of biodiversity were non-significantly different between the two systems. N-rd = number of comparisons and studies used to calculate the mean response ratios for restored versus degraded forests. N-rr $=$ number of comparisons and studies for restored versus reference forests. [Colour figure can be viewed at wileyonlinelibrary.com]

states (mean response ratios of -0.16 for logging and $-0 \cdot 18$ for mining).

\section{Effects of Restoration Age, Approaches and Geographic Regions on Forest Restoration Outcomes}

\section{Effects of restoration age}

Biodiversity and ecosystem functions showed varying degrees of improvement along the successive chronosequences (Figure 4). In comparisons of restored versus degraded forest, both measurements of biodiversity and ecosystem functions were markedly increased in restored forests. In all age clusters considered, increments of biodiversity were higher than that of ecosystem functions, although not significantly at $>20$ years after forest restoration began. Recovery of biodiversity and ecosystem functions showed similar patterns over time, with substantial increases at 0-30 years and declining increment at 30-60 years. In addition, results of linear mixed-effects models showed that response ratios

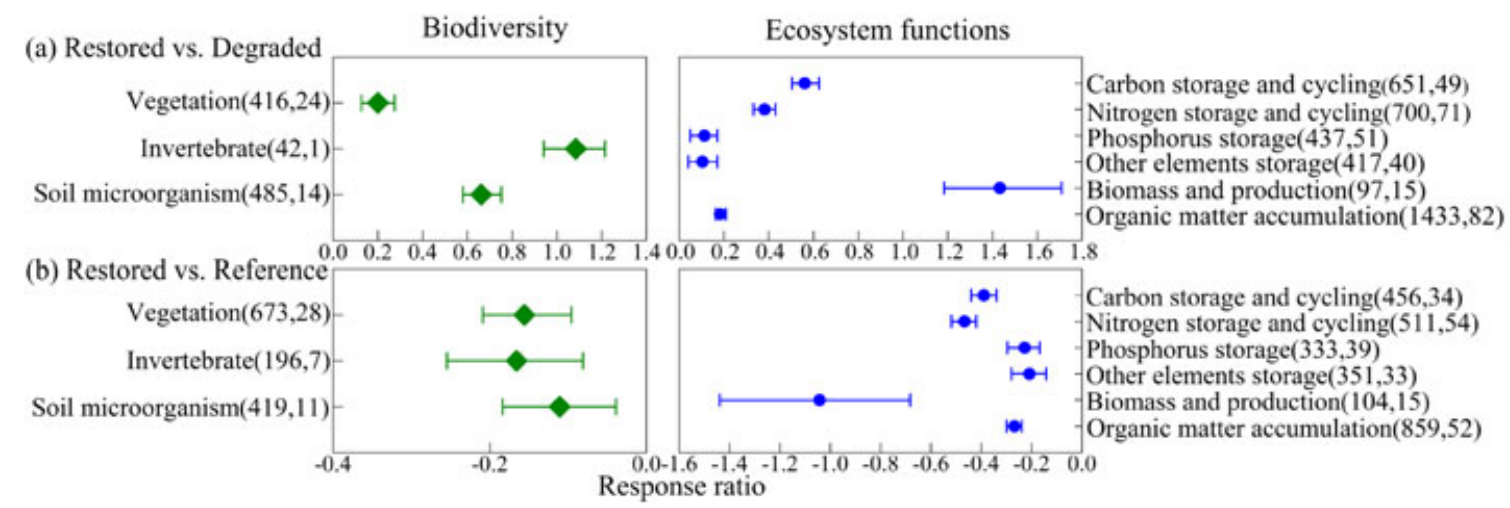

Figure 2. Mean response ratios for taxonomic groups and each group of ecosystem functions in comparisons of (a) restored versus degraded forests and (b) restored versus reference forests. Bars extending from the means denote bias-corrected $95 \%$ bootstrap confidence intervals. Numbers in parentheses indicate the number of comparisons and number of studies. [Colour figure can be viewed at wileyonlinelibrary.com] 

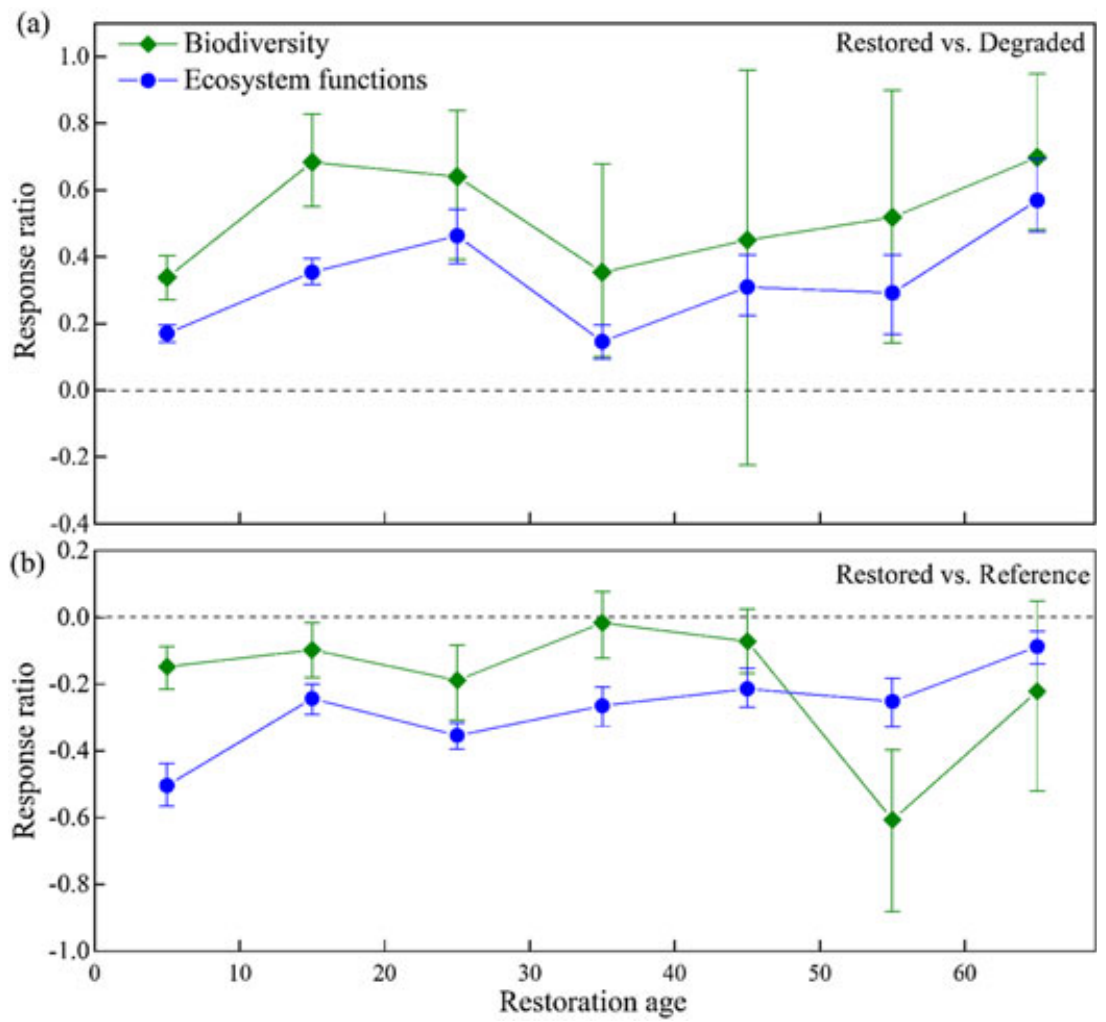

Figure 4. Recovery trajectory of biodiversity and ecosystem functions. (a) Comparisons of restored and degraded forests and (b) comparisons of restored and reference forests. [Colour figure can be viewed at wileyonlinelibrary.com]

for biodiversity and ecosystem functions were positively influenced by restoration age (Table II). In comparisons of restored versus reference forest, the measurements of biodiversity and ecosystem functions varied in a more complicated manner over time. Both measurements for biodiversity and ecosystem functions were lower in the restored forest than in the reference forest. Moreover, after less than 50 years of restoration efforts, the measurements for biodiversity in the restored forest were closer to the reference values than those of ecosystem functions.

\section{Effects of restoration approaches}

In both active and passive restoration approaches considered, measurements of biodiversity and ecosystem functions were significantly increased in restored forest, compared with the degraded states (i.e. bias-corrected 95\% CIs did not overlap zero) (Table III). The increments of biodiversity in areas involving natural or unassisted forest recovery were higher than those in areas where active restoration measures were implemented, and the same holds for ecosystem functions. The mean response ratios of biodiversity were significantly higher than those of ecosystem functions, regardless of the restoration approaches.

Regarding comparisons of restored and reference forests, measurements of biodiversity and ecosystem functions were significantly lower in restored forests than the reference states, except for biodiversity following passive restoration. For both biodiversity and ecosystem functions, passive approaches led the mean response ratios closer to zero than the active ones did. Moreover, the mean response ratios of biodiversity were closer to zero than those of ecosystem functions no matter if active or passive forest restoration was implemented.

\section{Effects of geographic regions}

Among the four ecological domains, measurements of biodiversity and ecosystem functions were significantly increased in the restored forest, compared with the degraded states, except for biodiversity in the north-eastern humid and semi-humid domain (Figure 1). The southern humid domain has the largest increments for both biodiversity and ecosystem functions, followed by the northern arid and semi-arid

Table III. Effects of restoration approach on biodiversity and ecosystem functions

\begin{tabular}{llll}
\hline & \multicolumn{1}{c}{$\ln R R$} & \multicolumn{1}{c}{ Bias CI } & Comparisons \\
\hline \multicolumn{4}{c}{ Restored vs degraded } \\
BD-active & 0.4293 & $(0 \cdot 3683,0 \cdot 4916)$ & 641 \\
BD-passive & $0 \cdot 5561$ & $(0 \cdot 4451,0 \cdot 6677)$ & 302 \\
EF-active & $0 \cdot 2807$ & $(0 \cdot 2495,0 \cdot 308)$ & 2,499 \\
EF-passive & $0 \cdot 329$ & $(0 \cdot 2921,0 \cdot 372)$ & 1,236 \\
\multicolumn{4}{c}{ Restored vs reference } \\
BD-active & $-0 \cdot 2561$ & $(-0 \cdot 3127,-0 \cdot 1936)$ & 610 \\
BD-passive & $-0 \cdot 0402$ & $(-0 \cdot 0943,0 \cdot 0125)$ & 678 \\
EF-active & $-0 \cdot 4057$ & $(-0 \cdot 4465,-0 \cdot 3696)$ & 1,553 \\
EF-passive & $-0 \cdot 2618$ & $(-0 \cdot 2988,-0 \cdot 2302)$ & 1,061 \\
\hline
\end{tabular}

$\mathrm{BD}=$ biodiversity $; \mathrm{EF}=$ ecosystem functions; Bias $\mathrm{CI}=$ bias-corrected $95 \%$ confidence interval; Comparisons $=$ number of comparisons used to calculate the mean response ratio $(\ln R R)$. 
domain and the Tibet Plateau domain. The north-eastern humid and semi-humid domain has the lowest increments for ecosystem functions, whereas no significant difference was observed for biodiversity in comparisons of restored and degraded forests. Similar to the results stated earlier, biodiversity showed more increments than ecosystem functions, except for the north-eastern humid and semihumid domain. As for comparisons between restored and reference forests, biodiversity of the north-eastern humid and semi-humid domain and the southern humid domain was significantly lower in the restored forest than in reference states. Biodiversity of the northern arid and semi-arid domain had no significant differences between the two systems. In addition, measurements of biodiversity in the Tibet Plateau domain in the restored forest were significantly higher than that in reference systems. Across the four ecological domains, there was still a significant disparity for ecosystem functions in the restored forest, compared with the reference states. After ecological restoration, measurements of ecosystem functions in the Tibet Plateau domain was closest to the reference values, followed by that in north-eastern humid and semi-humid domain, northern arid and semi-arid domain and southern humid domain.

Among the four representative ecoregions, biodiversity and ecosystem functions showed different degrees of recovery following active or passive restoration (Figure 5). After active restoration, the Sichuan-Chongqing ecoregion had higher (although not significantly) mean response ratios of biodiversity and ecosystem functions in comparisons of restored and degraded forests than the other three ecoregions did. As for comparisons of restored and reference forests, measurements of biodiversity and ecosystem functions in the Sichuan-Chongqing ecoregion were also closer to the reference values than that in the other three ecoregions.
After passive restoration, the Loess Plateau ecoregion had the lowest increments for biodiversity and ecosystem functions among the four ecoregions, in comparisons of restored versus degraded forests. In the two restoration approaches considered, biodiversity in the restored forest showed more increments, except for the Loess Plateau and South China ecoregions under active restoration, and was closer to the reference states than the ecosystem functions.

\section{DISCUSSION}

Taxonomic Groups, Measured Functional Variables and Reference Systems Matter for Gauging the Effectiveness of Forest Restoration

A previous global meta-analysis of a wide range of ecosystem types indicated that restoration enhanced biodiversity by an average of 44\% (Rey Benayas et al., 2009). Another global meta-analysis covering multiple taxonomic groups revealed that forest restoration increased biodiversity by $15-84 \%$, compared with degraded systems. The latter results were based on differences between the response ratios of restored and degraded forests, which were originally compared with reference systems in the source literature (Crouzeilles et al., 2016). We directly compare restored versus degraded forests and restored versus reference forests, which were consistent with the source literature. This implies that our study might be more understandable and reasonable. Our study focused only on forest ecosystems in China, which may be less accessible to the international community owing to language barriers. In our meta-analysis, 83 of the 172 selected studies were reported in Chinese, which were also important in evaluating the effectiveness of forest restoration.

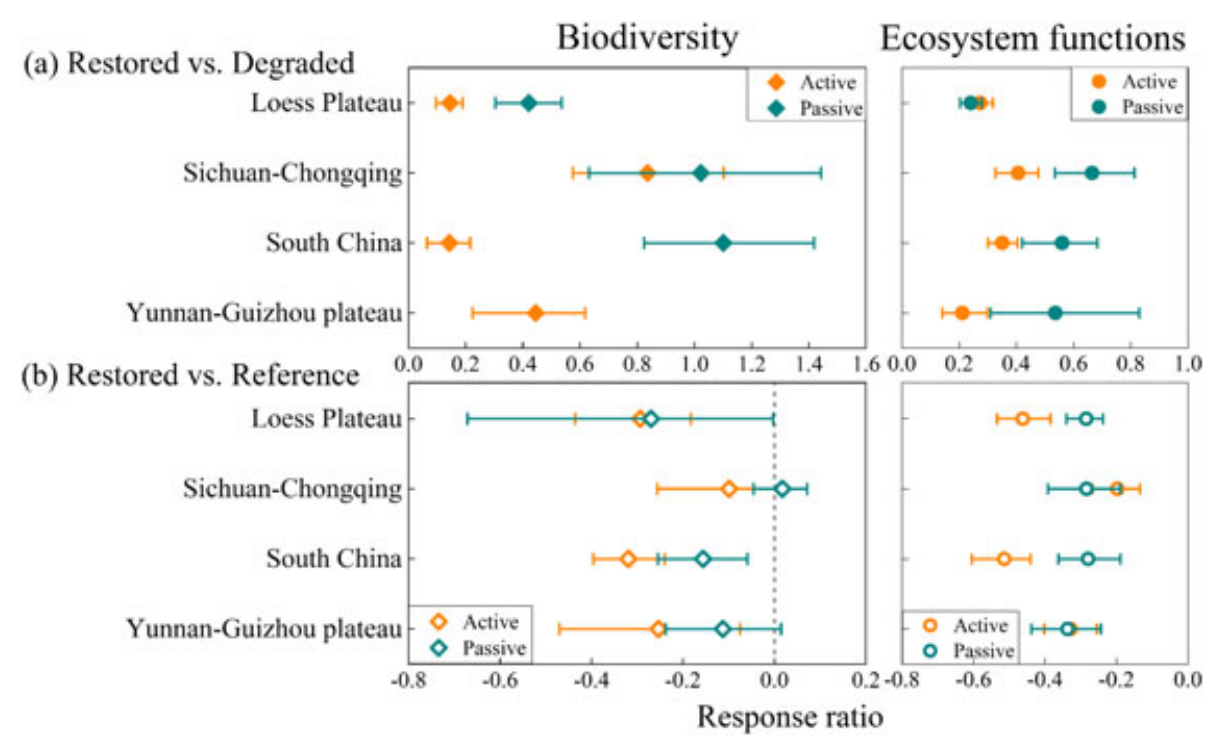

Figure 5. Effects of restoration approaches on biodiversity and ecosystem functions among the four representative ecoregions. (a) Comparisons of restored and degraded forests and (b) comparisons of restored and reference forests. Active = active restoration approach; Passive = passive restoration approach. In the comparisons of restored and degraded forests, there was no data for biodiversity in the Yunnan-Guizhou Plateau ecoregion following passive restoration. [Colour figure can be viewed at wileyonlinelibrary.com] 
Our results showed that in comparisons of restored versus degraded forests, the increment of biodiversity differs among taxonomic groups, with mean response ratios ranging from 0.2 to 1.08 . Among the three taxonomic groups, invertebrate showed the largest increment for biodiversity measures, followed by soil microorganism and vegetation. Numerous experimental studies have shown that some groups of invertebrates and soil microorganisms are very sensitive to environmental changes, which makes them effective indicators for monitoring habitat quality and biodiversity fluctuation (Brown, 1997; Bohac, 1999; Ohsawa, 2004; Li, 2011; Tang et al., 2014). Forest restoration activities would undoubtedly lead to great changes in their abundance and richness ( $\mathrm{Yu}$ et al., 2006). Besides, the number of measures we found to estimate biodiversity of invertebrates was less than that of vegetation and soil microorganisms, probably because of insufficient concerns for invertebrate research and strict data structure in the meta-analysis. This highlights an urgent need for more insightful multi-location experiments on invertebrates that allow for meta-analyses to be performed with detailed, balanced and diverse datasets.

From ecosystem functional perspectives, two global meta-analyses assessed the degrees of recovery of biogeochemical functions in restored wetlands (Moreno-Mateos et al., 2012; Moreno-Mateos et al., 2015). To the best of our knowledge, however, there are no comprehensive, quantitative studies involving ecosystem function recovery in a forest context in China and on the global scale, although such restorations are routinely implemented. For the first time, we performed systematic, evidence-based assessments of multiple ecosystem functions in forest restoration in China. Our results showed that measurements of biomass and production had the most increment in comparisons of restored versus degraded forests, followed by carbon and nitrogen storage and cycling, organic matter accumulation, phosphorus storage and other element storage, while, in comparisons of restored versus reference forests, recovery effectiveness of the six functional groups showed a different order. Measurements of ecosystem functions in the restored forest, showing great increment compared with the degraded state, were not necessarily the closest to the reference values. This simultaneously highlighted the need to choose a reference site in evaluating the effectiveness of forest restoration. Besides, biomass and production showed greater variability than the other functional groups. Former studies of forest biomass have acknowledged that forest biomass (aboveground biomass, root biomass and community biomass) could increase rapidly after disturbance activities (Vargas et al., 2007; West et al., 2014; Lin et al., 2015). Biomass, as the basis for matter and energy flux in forest ecosystems (Xiang 2010), was highly sensitive to management and restoration measures.

Previous studies have shown that reference sites are crucial and essential in the restoration of ecosystems, driving both the evaluation of current conditions and the setting of management targets for specific points in the future (Harris
\& Diggelen, 2006; Pollock et al., 2012; Crouzeilles \& Curran, 2016). An increasing number of studies concerning biomass, carbon, nutrient dynamics and soil properties have indicated a significant disparity between restored forests and natural forests (Hughes et al., 1999; Rodrigues Nogueira Jr et al., 2011; Liao et al., 2012). We compared the measures of biodiversity and ecosystem functions between restored and reference forests. The results indicated that measures of biodiversity and ecosystem functions were significantly lower in the restored forest than in the reference system, although forest restoration had contributed to various degrees of biodiversity and ecosystem function recovery. Restoration performance is limited: current restoration practice fails to recover the original levels of biodiversity and forest ecosystem functions, even after many decades. This makes primary forests, the reference sites in our study, an effectively irreplaceable biodiversity resource, and the basis for crucial ecosystem functions. The conclusions are in accordance with a former global study that assessed the impacts of disturbance and land conversion on biodiversity in tropical forests and revealed that there is no substitute for primary forests when it comes to maintaining tropical biodiversity (Gibson et al., 2011). Consequently, protecting the remaining primary forests by enhancing enforcement in existing protected areas, expanding comprehensive reserve networks and curbing international demand for forest commodities obtained at the expense of primary forests (Bengtsson et al., 2000; Rodrigues et al., 2004; Barlow et al., 2007; Gibson et al., 2011) continues to be one of the most important tasks for a wider biodiversity conservation and landscape management framework.

\section{Passive Restoration Can Be an Effective Strategy}

Natural recovery (passive restoration) currently restores more deforested lands than do tree plantations (Rey Benayas et al., 2008). During 2000-2005, natural regeneration has occurred over an estimated forest area of $45,000 \mathrm{~km}^{2} \mathrm{y}^{-1}$ worldwide, whereas $28,000 \mathrm{~km}^{2}$ of plantations was established per year (FAO, 2006). On a global scale, only a few countries, such as China and Chile, have established larger forest areas through plantations than through passive regeneration (FAO, 2006; Rey Benayas et al., 2008). The results of the eighth national survey of forest resources during 2009-2013 showed that the area of forests in China ranks the fifth around the world, whereas the area of plantations still ranks the first (SFA, 2014). Moreover, studies included in our meta-analysis reported more active restorations than passive approaches, with almost twice data entries in active restoration than the passive ones. Despite the increasing active restoration in China, with aims to facilitate the recovery process, evidence is growing that passive recovery could be an effective strategy and can achieve greater success than intensive interventions with fewer costs (Helmer, 2004; Prach et al., 2007; Letcher \& Chazdon, 2009).

Most direct comparisons of active and passive restoration in forests are based on individual field studies. Prach \& del Moral (2015) recommended that a meta-analysis to compare 
passive and active restoration in a variety of habitats and geographical regions is needed for broader generalization of the effects of different restoration approaches. Indeed, our study is exactly in response to this need. Our metaanalysis showed that passive restoration approaches performed better than the active ones not only from a general point of view, with the response ratios of biodiversity and ecosystem functions following passive restoration larger than that of active restoration, but also among the four representative ecoregions. In most cases shown in Figure 5 (12 of 15 pairwise groups: biodiversity and ecosystem function $\times$ four ecoregions $\times$ two comparison types, with one exception of biodiversity in the Yunnan-Guizhou Plateau ecoregion in comparisons of restored vs degraded forest), passive restoration led to more increments of biodiversity and ecosystem functions and fewer differences with reference values than the active approaches did. This occurs probably because when plantations were established, considerable aboveground biomass was removed and site preparation, slash thinning and weed control can lead to little or no understorey herbaceous cover under plantations (Chen et al., 2005; Zheng et al., 2008; Berthrong et al., 2009), while natural regeneration may contain more mature trees, native shrub species and coarse woody debris than plantations (Smith et al., 2015). On the other hand, more of the local flora and fauna may prefer joining the developing vegetation than that in directed projects as sown or planted species often preclude the spontaneous establishment of less competitive species and lead to more homogenous environment (Tropek et al., 2012).

In general, approaches to restore forest ecosystems depend strongly on degradation origins, landscape context, restoration goals and available resources (Chazdon, 2008; Prach \& Hobbs, 2008; Holl \& Aide, 2011). For systems where degradation and landscape context are inhibiting natural recovery, active restoration would be necessary to initiate the recovery process. For example, in some severely degraded lands resulting from mines, it may be necessary and critical to use active measures to facilitate recovery, because abiotic factors, such as soil removal or toxic substrata, may limit establishment of native vegetation and generate a short-term acute threat to human health (Koch \& Hobbs, 2007; Prach et al., 2007; Holl \& Aide, 2011).

In addition, in many restoration projects, the main goal is to revegetate a site as soon as possible, either to reduce erosion and sedimentation and improve water quality or to increase productivity (Wali et al., 2002; Liu et al., 2013). For example, China's programmes for transforming farmland into forests or grasslands were implemented in steep slopes, such as the Loess Plateau in our study. In these low-productivity sites, where the climate is less favourable than that in warmer and humid areas and vegetation cover is sparse and forms slowly, various active measures are necessary and advocated. Finally, the common case of limited funding and labour will often constrain the goal setting and scales of restoration projects and simultaneously highlight the need to consider whether passive recovery is a proper option and how to optimize resource arrangement (Holl \& Aide, 2011).

On the basis of the earlier analysis, we advocated using passive recovery, especially where environmental site conditions are favourable for spontaneous succession, such as in the southern humid domain in our study that has the largest increments for both biodiversity and ecosystem functions among the four ecological domains. In addition, passive recovery is also preferable when the conditions are too harsh for human-aided restoration to be cost-effective. Considering the four dependent factors stated earlier, it may be advisable to implement an adaptive management approach that combines passive regeneration with the active approach according to the recovery potential of the target sites. An excellent example of this adaptive approach being applied at a regional scale is the restoration of Atlantic Forest biome in Brazil, which has categorized nearly 500,000-ha lands along a gradient of potential to natural recovery, ranging from those that have low potential for recovery necessitating extensive planting to those undergoing pioneer establishment with enrichment planting needed to those that can naturally recovery without the need of intervention (Rodrigues et al., 2011).

\section{The Biodiversity-Ecosystem Function Approach to Ecological Forest Restoration}

It is important to incorporate insights from the relationship between biodiversity and stability of ecosystem functioning into forest restoration projects. Unfortunately, there is a strong spatial mismatch between the numerous small-scale experiments and large-scale management concerns (Snelgrove et al., 2014), which constrains the implementation of ecosystem perspectives in decision-making and management. If we hope to advise management and conservation more effectively on the conversion of biodiversity loss and restoration of forest ecosystems, we must quickly bridge the chasm. In our study, we firstly tried to quantify the changes of biodiversity and ecosystem functions in the forest restoration process, as well as identify the influence factors. In some sense, our study is bridging the gap of simplified, small-scale studies and broad-scale needs of society and policymakers, in response to linking biodiversity and ecosystem functions and developing strategies to ensure their sustainability. In our study, we concluded general patterns of biodiversity and ecosystem function recovery and found that biodiversity in restored forests showed more increments and was closer to the reference states than the ecosystem functions. This suggested that biodiversity, the structural component of ecosystems, might often be necessary to achieve functional recovery (MorenoMateos et al., 2012). However, only focusing on the species richness and structural components could be far insufficient for the recovery of ecological functions because the measured functional variables could be much lower for the structurally restored forests than their reference systems. Therefore, we strongly recommend incorporating both structural components including species diversity and ecosystem 
functions during the planning, implementation and performance assessment phases of forest restoration programmes for sustainable and adaptive forest ecosystem management.

\section{Further Considerations}

In our study, we identified four influence factors on the effectiveness of biodiversity and ecosystem function recovery. There are, however, several factors that may also affect forest restoration, such as climate (rainfall and heat) and seed resource availability (Zheng et al., 2004; Ren et al., 2007; Rey Benayas et al., 2009). The different restoration responses observed in the large ecological domains in our analysis here could coarsely reflect the impacts of climate factors (Figure 1). Unfortunately, very few selected studies reported climate manipulation experiments and relevant information about the seed resource availability, so it is hard to include these factors in this meta-analysis. This can remind us to consider more factors in forest restoration research and applications to deepen our scientific understanding of the systematic interactions incurred by restoration process, which will largely contribute to real-world forest restoration performance on improving biodiversity and ecosystem functions across spatiotemporal scales.

\section{ACKNOWLEDGMENTS}

We thank all the authors who shared their original data for developing this study. This research was supported by the National Natural Science Foundation of China (no. 41571130083) and the National Key Research and Development Program of China (no. 2016YFC0501601). There is no conflict of interest.

\section{REFERENCES}

Aerts R, Honnay O. 2011. Forest restoration, biodiversity and ecosystem functioning. BMC Ecology 11: 29-29. https://doi.org/10.1186/14726785-11-29.

Ahrends A, Burgess ND, Milledge SA, Bulling MT, Fisher B, Smart JC, Clarke GP, Mhoro BE, Lewis SL. 2010. Predictable waves of sequential forest degradation and biodiversity loss spreading from an African city. Proceedings of the National Academy of Sciences of the United States of America 107: 14556-14561. https://doi.org/10.1073/ pnas.0914471107.

Barlow J, Gardner TA, Araujo IS, Avila-Pires TC, Bonaldo AB, Costa JE Esposito MC, Ferreira LV, Hawes J, Hernandez MI, Hoogmoed MS, Leite RN, Lo-Man-Hung NF, Malcolm JR, Martins MB, Mestre LA Miranda-Santos R, Nunes-Gutjahr AL, Overal WL, Parry L, Peters SL, Ribeiro-Junior MA, da Silva MN, da Silva MC, Peres CA. 2007. Quantifying the biodiversity value of tropical primary, secondary, and plantation forests. Proceedings of the National Academy of Sciences of the United States of America 104: 18555-18560. https://doi.org/10.1073/ pnas.0703333104

Barral MP, Rey Benayas JM, Meli P, Maceira NO. 2015. Quantifying the impacts of ecological restoration on biodiversity and ecosystem services in agroecosystems: a global meta-analysis. Agriculture Ecosystems \& Environment 202: 223-231. https://doi.org/10.1016/j.agee.2015.01.009.

Bengtsson J, Nilsson SG, Franc A, Menozzi P. 2000. Biodiversity, disturbances, ecosystem function and management of European forests. Forest Ecology and Management 132: 39-50. https://doi.org/10.1016/S03781127(00)00378-9.

Berthrong ST, Jobbagy EG, Jackson RB. 2009. A global meta-analysis of soil exchangeable cations, $\mathrm{pH}$, carbon, and nitrogen with afforestation.
Ecological Applications 19: 2228-2241. https://doi.org/10.1890/081730.1.

Bohac J. 1999. Staphylinid beetles as bioindicators. Agriculture Ecosystems \& Environment 74: 357-372. https://doi.org/10.1016/S0167-8809(99) 00043-2.

Brown KS. 1997. Diversity, disturbance, and sustainable use of Neotropical forests: insects as indicators for conservation monitoring. Journal of Insect Conservation 1: 25-42. https://doi.org/10.1023/A:1018422807610.

Burnham KP, Anderson DR. 2002. Model selection and multimodel inference: a practical information-theoretic approach. Springer-Verlag: New York.

CBD. 2010. COP10 decision $X / 2$. Strategic plan for biodiversity 2011-2020. Convention on Biological Diversity.

Chazdon RL. 2008. Beyond deforestation: restoring forests and ecosystem services on degraded lands. Science 320: 1458-1460. https://doi.org/ 10.1126/science. 1155365 .

Chen GS, Yang YS, Xie JS, Guo JF, Gao R, Qian W. 2005. Conversion of a natural broad-leafed evergreen forest into pure plantation forests in a subtropical area: effects on carbon storage. Annals of Forest Science 62 : 659-668. https://doi.org/10.1051/forest:2005073.

Cole LES, Bhagwat SA, Willis KJ. 2014. Recovery and resilience of tropical forests after disturbance. Nature Communications 5: 3906. https:// doi.org/10.1038/ncomms4906.

Crouzeilles R, Curran M. 2016. Which landscape size best predicts the influence of forest cover on restoration success? A global meta-analysis on the scale of effect. Journal of Applied Ecology 53: 440-448. https:// doi.org/10.1111/1365-2664.12590.

Crouzeilles R, Curran M, Ferreira MS, Lindenmayer DB, Grelle CE, Rey Benayas JM. 2016. A global meta-analysis on the ecological drivers of forest restoration success. Nature Communications 7: 11666. https:// doi.org/10.1038/ncomms11666.

Curran M, Hellweg S, Beck J. 2014. Is there any empirical support for biodiversity offset policy? Ecological Applications 24: 617-632. https://doi. org/10.1890/13-0243.1.

DeFries RS, Rudel T, Uriarte M, Hansen M. 2010. Deforestation driven by urban population growth and agricultural trade in the twenty-first century. Nature Geoscience 3: 178-181. https://doi.org/10.1038/ngeo756.

Ding Y, Zang RG, Liu SR, He FL, Letcher SG. 2012. Recovery of woody plant diversity in tropical rain forests in southern China after logging and shifting cultivation. Biological Conservation 145: 225-233. https://doi. org/10.1016/j.biocon.2011.11.009.

FAO. 2006. Global forest resources assessment 2005: Progress towards sustainable forest management. Food and Agriculture Organization of the United Nations: Rome, Italy.

Gibson L, Lee TM, Koh LP, Brook BW, Gardner TA, Barlow J, Peres CA, Bradshaw CJ, Laurance WF, Lovejoy TE, Sodhi NS. 2011. Primary forests are irreplaceable for sustaining tropical biodiversity. Nature $\mathbf{4 7 8}$ : 378-381. https://doi.org/10.1038/nature10425.

Gurevitch J, Hedges LV. 2001. Meta-analysis: combining the results of independent experiments. Oxford University Press: Oxford, UK; 347-369.

Harris JA, Diggelen R. 2006. Restoration ecology. Blackwell Publishing: Oxford, UK.

Helmer EH. 2004. Forest conservation and land development in Puerto Rico. Landscape Ecology 19: 29-40. https://doi.org/10.1023/B LAND.0000018364.68514.fb.

Holl KD, Aide TM. 2011. When and where to actively restore ecosystems? Forest Ecology and Management 261: 1558-1563. https://doi.org/ 10.1016/j.foreco.2010.07.004.

Hughes RF, Kauffman JB, Jaramillo VJ. 1999. Biomass, carbon, and nutrient dynamics of secondary forests in a humid tropical region of Mexico. Ecology 80: 1892-1907.

Jacobs DF, Oliet JA, Aronson J, Bolte A, Bullock JM, Donoso PJ, Landhäusser SM, Madsen P, Peng S, Rey-Benayas JM, Weber JC. 2015. Restoring forests: what constitutes success in the twenty-first century? New Forests 46: 601-614. https://doi.org/10.1007/s11056-015-9513-5.

Koch JM, Hobbs RJ. 2007. Synthesis: is Alcoa successfully restoring a Jarrah forest ecosystem after bauxite mining in Western Australia? Restoration Ecology 15: S137-S144. https://doi.org/10.1111/j.1526100X.2007.00301.X.

Lamb D, Stanturf J, Madsen P. 2012. What is forest landscape restoration? In Forest landscape restoration. Springer Netherlands: Dordrecht.

Letcher SG, Chazdon RL. 2009. Rapid recovery of biomass, species richness, and species composition in a forest chronosequence in northeastern Costa Rica. Biotropica 41: 608-617. https://doi.org/10.1111/j.17447429.2009.00517.x. 
Li WH. 2004. Degradation and restoration of forest ecosystems in China. Forest Ecology and Management 201: 33-41. https://doi.org/10.1016/j. foreco.2004.06.010.

Li T. 2011. The research of soil animal in converting farmland to forestations in Ruichang limestone mountain. Jiangxi Agricultural University: Nan Chang.

Liang YM, He XY, Chen CY, Feng SZ, Liu L, Chen XB, Zhao ZW, Su YR. 2015. Influence of plant communities and soil properties during natural vegetation restoration on arbuscular mycorrhizal fungal communities in a karst region. Ecological Engineering 82: 57-65. https://doi.org/ 10.1016/j.ecoleng.2015.04.089.

Liao C, Luo Y, Fang C, Chen J, Li B. 2012. The effects of plantation practice on soil properties based on the comparison between natural and planted forests: a meta-analysis. Global Ecology and Biogeography 21: 318-327. https://doi.org/10.1111/j.1466-8238.2011.00690.x.

Lin DM, Lai JS, Yang B, Song P, Li N, Ren HB, Ma KP. 2015. Forest biomass recovery after different anthropogenic disturbances: relative importance of changes in stand structure and wood density. European Journal of Forest Research 134: 769-780. https://doi.org/10.1007/ s10342-015-0888-9.

Liu SL, Dong YH, Li D, Liu Q, Wang J, Zhang XL. 2013. Effects of different terrace protection measures in a sloping land consolidation project targeting soil erosion at the slope scale. Ecological Engineering 53: 46-53. https://doi.org/10.1016/j.ecoleng.2012.12.001.

Liu SL, Dong YH, Deng L, Liu Q, Zhao HD, Dong SK. 2014. Forest fragmentation and landscape connectivity change associated with road network extension and city expansion: a case study in the Lancang River valley. Ecological Indicators 36: 160-168. https://doi.org/10.1016/j. ecolind.2013.07.018.

Marín-Spiotta E, Sharma S, Ramankutty N. 2013. Carbon storage in successional and plantation forest soils: a tropical analysis. Global Ecology and Biogeography 22: 105-117. https://doi.org/10.1111/j.14668238.2012.00788.x.

Meli P, Rey Benayas JM, Balvanera P, Ramos MM. 2014. Restoration enhances wetland biodiversity and ecosystem service supply, but results are context dependent: a meta-analysis. PloS One 9 . https://doi.org/10.1371/ journal.pone.0093507.t001.e93507

Moreno-Mateos D, Power ME, Comin FA, Yockteng R. 2012. Structural and functional loss in restored wetland ecosystems. PLoS Biology 10 . https://doi.org/10.1371/journal.pbio.1001247.e1001247

Moreno-Mateos D, Meli P, Vara-Rodríguez MI, Aronson J, Strecker A. 2015. Ecosystem response to interventions: lessons from restored and created wetland ecosystems. Journal of Applied Ecology 52: 1528-1537. https://doi.org/10.1111/1365-2664.12518.

Ohsawa M. 2004. Species richness of Cerambycidae in larch plantations and natural broad-leaved forests of the central mountainous region of Japan. Forest Ecology and Management 189: 375-385. https://doi.org/ 10.1016/j.foreco.2003.09.007

Oliver CD. 2014. Functional restoration of social-forestry systems across spatial and temporal scales. Journal of Sustainable Forestry 33: S123-S148. https://doi.org/10.1080/10549811.2014.884003.

Pollock MM, Beechie TJ, Imaki H. 2012. Using reference conditions in ecosystem restoration: an example for riparian conifer forests in the Pacific northwest. Ecosphere 3. https://doi.org/10.1890/es12-00175.1.

Prach K, del Moral R. 2015. Passive restoration is often quite effective: response to Zahawi et al. (2014). Restoration Ecology 23: 344-346. https:// doi.org/10.1111/rec.12224.

Prach K, Hobbs RJ. 2008. Spontaneous succession versus technical reclamation in the restoration of disturbed sites. Restoration Ecology 16: 363-366. https://doi.org/10.1111/j.1526-100X.2008.00412.x.

Prach K, Marrs R, Pysek P, Rv D. 2007. Linking restoration and ecological succession. Springer: New York.

Ren H, Li Z, Shen W, Yu Z, Peng S, Liao C, Ding M, Wu J. 2007. Changes in biodiversity and ecosystem function during the restoration of a tropical forest in South China. Science in China Series C-Life Sciences 50: 277-284. https://doi.org/10.1007/s11427-007-0028-y.

Ren H, Lu HF, Wang J, Liu N, Guo QF. 2011. Forest restoration in China: advances, obstacles, and perspectives. Tree and Forestry Science and Biotechnology 6: 7-16.

Rey Benayas JM, Bullock JM, Newton AC. 2008. Creating woodland islets to reconcile ecological restoration, conservation, and agricultural land use. Frontiers in Ecology and the Environment 6: 329-336. https://doi. org/10.1890/070057.

Rey Benayas JM, Newton AC, Diaz A, Benayas JM. 2009. Enhancement of biodiversity and ecosystem services by ecological restoration: a meta- analysis. Science 325: 1121-1124. https://doi.org/10.1126/ science. 1172460.

Rodrigues Nogueira Jr L, De Moraes Gonçalves JL, Lex Engel V, Parrotta J. 2011. Soil dynamics and carbon stocks 10 years after restoration of degraded land using Atlantic Forest tree species. Forest Systems 20: 536. https://doi.org/10.5424/fs/20112003-11844.

Rodrigues AS, Andelman SJ, Bakarr MI, Boitani L, Brooks TM, Cowling RM, Fishpool LD, Da Fonseca GA, Gaston KJ, Hoffmann M, Long JS, Marquet PA, Pilgrim JD, Pressey RL, Schipper J, Sechrest W, Stuart SN, Underhill LG, Waller RW, Watts ME, Yan X. 2004. Effectiveness of the global protected area network in representing species diversity. Nature 428: 640-643. https://doi.org/10.1038/nature02422.

Rodrigues RR, Gandolfi S, Nave AG, Aronson J, Barreto TE, Vidal CY, Brancalion PHS. 2011. Large-scale ecological restoration of highdiversity tropical forests in SE Brazil. Forest Ecology and Management 261: 1605-1613. https://doi.org/10.1016/j.foreco.2010.07.005.

Rosenberg MS. 2005. The file-drawer problem revisited: a general weighted method for calculating fail-safe numbers in meta-analysis. Evolution 59: 464-468.

Rosenberg MS, Adams DC, Gurevitch J. 2000. MetaWin: statistical software for meta-analysis. Sinauer Associates Sunderland.

Rosenthal R. 1979. The 'file drawer problem' and tolerance for null results. Psychological Bulletin 86: 638-641.

SFA. 2014. The 8th forest resources inventory results in China. China's State Forestry Administration.

Smith GC, Lewis T, Hogan LD. 2015. Fauna community trends during early restoration of alluvial open forest/woodland ecosystems on former agricultural land. Restoration Ecology 23: 787-799. https://doi.org/ 10.1111/rec.12269.

Snelgrove PV, Thrush SF, Wall DH, Norkko A. 2014. Real world biodiversity-ecosystem functioning: a seafloor perspective. Trends in Ecology \& Evolution 29: 398-405. https://doi.org/10.1016/j. tree.2014.05.002.

Spake R, Ezard THG, Martin PA, Newton AC, Doncaster CP. 2015. A meta-analysis of functional group responses to forest recovery outside of the tropics. Conservation Biology 29: 1695-1703. https://doi.org/ 10.1111/cobi.12548.

Stanturf JA, Palik BJ, Dumroese RK. 2014. Contemporary forest restoration: a review emphasizing function. Forest Ecology and Management 331: 292-323. https://doi.org/10.1016/j.foreco.2014.07.029.

Tang CQ, He LY, Su WH, Zhang GF, Wang HC, Peng MC, Wu ZL, Wang CY. 2013. Regeneration, recovery and succession of a Pinus yunnanensis community five years after a mega-fire in Central Yunnan, China. Forest Ecology and Management 294: 188-196. https://doi.org/10.1016/j. foreco.2012.07.019.

Tang Z, Li JG, Li H, Zhang LM, Li ZF, Lou YL. 2014. Rapid responses of soil microbes and active organic carbon to eco-restoration in karst region. Ecology and Environmental Sciences 23: 1130-1135. https://doi.org/ 10.16258/j.cnki.1674-5906.2014.07.022.

Tropek R, Kadlec T, Hejda M, Kocarek P, Skuhrovec J, Malenovsky I, Vodka S, Spitzer L, Banar P, Konvicka M. 2012. Technical reclamations are wasting the conservation potential of post-mining sites. A case study of black coal spoil dumps. Ecological Engineering 43: 13-18. https://doi. org/10.1016/j.ecoleng.2011.10.010.

Vargas R, Allen MF, Allen EB. 2007. Biomass and carbon accumulation in a fire chronosequence of a seasonally dry tropical forest. Global Change Biology 14: 109-124. https://doi.org/10.1111/j.13652486.2007.01462.x

Wali MK, Safaya NM, Evrendilek F. 2002. Handbook of ecological restoration. Cambridge University Press: Cambridge, UK.

West TAP, Vidal E, Putz FE. 2014. Forest biomass recovery after conventional and reduced-impact logging in Amazonian Brazil. Forest Ecology and Management 314: 59-63. https://doi.org/10.1016/j. foreco.2013.11.022.

Xiang ZY. 2010. Study on the biomass and nutrient distribution of different patterns vegetation restoration stand in rocky desertification area in Shaoyang county. Central South University of Forestry \& Technology: Chang Sha.

Xie GD, Zhang CS, Zhang LB, Su D, Cao SY, Leng YF, Xiao Y. 2012. China's county-scale ecological regionalization. Journal of Natural Resources 27: 154-162.

Yu XD, Luo TH, Yang J, Zhou HZ. 2006. Diversity of ground-dwelling beetles (Coleoptera) in larch plantation with different stages of reforestation in Wolong natural reserve, southwestern China. Zoological Research 27: $1-11$. 
Zhang S, Zhang YX, Ma KM, Shefferson R. 2016. Latitudinal variation in herbivory: hemispheric asymmetries and the role of climatic drivers. Journal of Ecology 104: 1089-1095. https://doi.org/10.1111/ 1365-2745.12588.

Zheng H, Ouyang ZY, Wang XK, Peng TB, Li ZX, Zhao TQ, Li XQ. 2004 Studies on the characteristics of soil seed banks under different forest restoration types in hilly red soil region, southern China. Journal of Natural Resources 19: 361-368.

Zheng H, Ouyang ZY, Xu WH, Wang XK, Miao H, Li XQ, Tian YX. 2008 Variation of carbon storage by different reforestation types in the hilly red soil region of southern China. Forest Ecology and Management 255: 1113-1121. https://doi.org/10.1016/j.foreco.2007.10.015.

\section{SUPPORTING INFORMATION}

Additional Supporting Information may be found online in the supporting information tab for this article.

Table S2. Variables for biodiversity simultaneously in restored and degraded (or reference) forest.

Table S3. Variables for ecosystem functions simultaneously in restored and degraded (or reference) forest.
Table S4. Database for restored versus degraded forest.

Table S5. Database for restored versus reference forest.

Table S6. Percentage change of biodiversity and ecosystem functions.

Table S7. Results of the model comparison.

Appendix S1. Studies used in the meta-analysis.

Appendix S2. Methodological details for the meta-analysis (Table S1 included).

Appendix. S3. SAS scripts for linear mixed-effects model estimation. 